\title{
Development of controlled release formulations of thiabendazole
}

\author{
Yasser Z. El-Nahhal \\ Department of Earth and Environmental Science, Faculty of Science, The Islamic University-Gaza, Gaza, Palestine; \\ y_el_nahhal@hotmail.com
}

Received 11 September 2013; revised 25 October 2013; accepted 6 November 2013

Copyright (C) 2014 Yasser Z. El-Nahhal. This is an open access article distributed under the Creative Commons Attribution License, which permits unrestricted use, distribution, and reproduction in any medium, provided the original work is properly cited. In accordance of the Creative Commons Attribution License all Copyrights @ 2014 are reserved for SCIRP and the owner of the intellectual property Yasser Z. El-Nahhal. All Copyright (C) 2014 are guarded by law and by SCIRP as a guardian.

\section{ABSTRACT}

This study aimed to develop controlled release formulation of Thiabendazole for reduced contaminations to soil water and agricultural produces. The idea behind this work was based on changing the ionization status of Thiabendazole molecule throughout $\mathrm{pH}$ changes to become a cation then adsorbing it to bentonite clay surfaces. Equilibrium concentrations of Thiabendazole in the adsorption solutions were determined by HPLC. Results showed that Thiabendazole was better adsorbed in clay at the lowest $\mathrm{pH}$ value (pH 3). Furthermore, raising the temperature of the adsorption reaction increased the adsorbed amount of Thiabendazole. Release experiments showed that Thiabendazole is extremely slower at $\mathrm{pH} 3$ than at $\mathrm{pH} 5.5$ or $\mathrm{pH} 9$. These promising results suggest that application of Thiabendazole clay based formulation may reduce the applied rate and that the released fraction consequently may reduce the environmental contamination. It is also advantageous to use these formulations in the acidic soil for plant disease control.

\section{KEYWORDS}

Thiabendazole; Adsorption; Controlled Release; $\mathrm{pH}$; Bentonite

\section{INTRODUCTION}

Fungicides are essential agricultural materials needed to protect the agricultural products and to improve its quality. However, the frequent applications of fungicides to control plant diseases may have resulted in accumulation of their residues in plant tissues. Previous review
[1] showed that residues of pesticides have been detected in many agricultural products in the Meddle East countries. For instance fenitrothion residues were detected in potato sample from Egypt [2], dicofol residues were detected in cucumber in Jordan [3], captan, thiabendazole , vinclozolin fenuron residues were detected in may agricultural products in Kuwait [4], fenvalerate residues were detected in apple samples in Pakistan [5], attabron triadiminol residues were detected in tomato and potato samples in Palestine [6], captafol residues were detected in a wheat monoculture after prolonged application in Germany [7], fludioxonil residues were found in citrus fruits in Italy [8]. However, fungicide residues have been detected in runoff from golf courses, under Scandinavian conditions [9], tricyclazole residues were found in rice paddy watersheds in Italy [10]. Carbendazim residues were detected in surface water samples in Chile [11]. Thiabendazole residues have been detected in citrus samples [12], in fruit-based soft drinks [13], in apple juice concentrate [14], in lemons [15], in water samples [16], in sea port water and in sediment samples [17], in foodstuffs [18], in the UK mushroom industry [19]. Furthermore, Thiabendazole application creates eco-toxicity, for instance, Castillo et al. [20] found a macroinvertebrate community changes following thiabendazole applications in a banana plantation. Kim et al. [21] studied the Sorption of benzimidazole anthelmintics to dissolved organic matter and sewage sludge. They found that the correlations between $\log \mathrm{K}_{\mathrm{oc}}$ and $\log \mathrm{K}_{\mathrm{ow}}$ were weak and the magnitude of the sorption coefficients to the hydrophilic organic matters (hydroxypropyl-beta-cyclodextrin and sewage sludge) were similar to or slightly smaller than those for the hydrophobic organic matters (humic acids and liposome).

García Calzón et al. [22] studied the adsorption of Thiabendazole at a Mercury/Solution Interface. They found a state of normal adsorption and a condensed two- 
dimensional layer at moderately charged and rather negatively charged surfaces. Spanoghe et al. [23] studied the fate of Thiabendazole during storage, handling and forcing of chicory. They concluded that Thiabendazole residues applied before storage are still present on the roots at the start of the forcing cycle. Furthermore, previous study [24] indicated that Thiabendazole appears to have some mobility in sand, silt loam, and sandy loam, but shows no mobility in clay. As obvious, residues of Thiabendazole have been found in many agricultural products and environmental samples. These residues may have adverse human health effects. Consequently, initiative steps must be taken to reduce the accumulation of these residues in fruit, vegetable and environmental samples and consequently reduce the health hazards. One approach to achieve this is to adsorb Thiabendazole molecules to clay minerals under different $\mathrm{pH}$ values that change the ionization status of Thiabendazole from hydrophobic and/or anionic form to cationic one consequently it can strongly be adsorbed to clay surface via cation exchange reaction.

This study is initiated to develop clay based formulations that controlled the release of Thiabendazole to soil environment consequently reduce the possible accumulation in plant tissues and to investigate the effect of different parameters on the fate of Thiabendazole.

\section{MATERIALS AND METHODS}

Materials. We used a $\mathrm{Ca}^{2+}$-bentonite from Greece (Milos, Prassa Carys, mined 1992, M48). The reason behind using a $\mathrm{Ca}^{2+}$-bentonite clay because it contains about $95 \% \mathrm{Ca}^{2+}$-montmorillonite which have high cation exchange capacity (CEC) ranged $80-120 \mathrm{mmol} / \mathrm{g}$ clay [25]. Thiabendazole (HPLC grade, 2-(thiazole-4-yl)benzimidazole; 2-(1,3-thiazol-4-yl) benzimidazole, molecular weight 201.3, (Figure 1) was purchased from Fluka (Germany). It is hydrophobic with an octanol/water partitioning coefficient $\mathrm{K}_{\mathrm{ow}} \log \mathrm{P}=2.39(\mathrm{pH} 7)$, and solubility in water $160 \mathrm{mg} / \mathrm{L}(\mathrm{pH}$ 4), and $30 \mathrm{mg} / \mathrm{L}$ (pH 7 - 10). It has a pKa value 4.73 [26].

\subsection{Adsorption Experiments}

Influence of time on the adsorption of Thiabendazole: The stock solution of Thiabendazole was prepared by dissolving $31.9 \mathrm{mg}$ in $2-3 \mathrm{~mL}$ methanol and diluting to $1 \mathrm{~L}$ with deionized water. The low concentration of methanol in the adsorption experiments had no influence on linuron adsorption.

Appropriate amounts of Thiabendazole equivalent to $30 \mathrm{mg} / \mathrm{g}$ clay were transferred to a $30 \mathrm{ml}$ centrifugation tubes and diluted with water up to $25 \mathrm{ml}$. The tubes were kept under rotary shaking for 4, 6, 24 and $30 \mathrm{hr}$. The tubes were centrifuged at $20,000 \mathrm{~g}$ to separate the clay par-

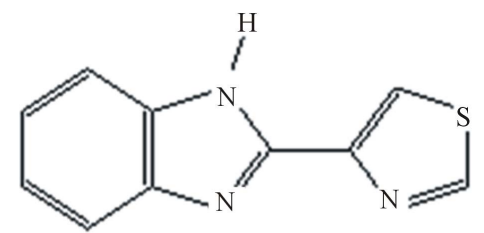

Figure 1. Chemical structure of Thiabendazole.

ticles. The equilibrium concentrations of Thiabendazole in supernatants were determined by HPLC as described below.

\subsection{Adsorption Isotherm}

The adsorption of Thiabendazole on the bentonite was measured at $22^{\circ} \mathrm{C} \pm 2{ }^{\circ} \mathrm{C}$. Appropriate aliquots of the aqueous stock solution of Thiabendazole were diluted with water to $25 \mathrm{~mL}$ and added to $5 \mathrm{mg}$ bentonite in 30-mL centrifuge tubes. The concentration of Thiabendazole ranged between 1.2 and $31.9 \mathrm{mg} / \mathrm{L}$. The final concentration of bentonite was $0.2 \mathrm{~g} / \mathrm{L}$. The dispersions were kept under continuous rotary agitation during 48 hours. The supernatant was separated by centrifugation at $20,000 \mathrm{~g}$ for $0.5 \mathrm{~h}$.

The concentration of Thiabendazole in the supernatants was determined by Waters 717 HPLC with UV detector (detection wavelength $299 \mathrm{~nm}$ ). Column: NovaPak C18 (inner diameter $3.9 \mathrm{~mm}$, length $150 \mathrm{~mm}$ ), flow rate: $1 \mathrm{~mL} / \mathrm{min}$. The mobile phase was methanol/water $50 / 50(\mathrm{v} / \mathrm{v})$. The water phase contained $0.5 \%$ ammonium hydroxide (25\%). The run time was 6 min and retention time is $\sim 3.825 \pm 0.124$. The injection rate was $25 \mu \mathrm{l}$.

The relationship between concentrations of Thiabendazole and peak areas of the HPLC chromatogram was linear for 0.388 - $6.38 \mathrm{mg} / \mathrm{L}$ Thiabendazole. Linear regression was used to determine the equilibrium concentration of Thiabendazole in the solutions. The regression showed $\mathrm{R}^{2}$ value close to unity (0.9997). The amount of Thiabendazole adsorbed (correctly the specific reduced surface excess $\mathrm{n}^{\sigma(\mathrm{n})} / \mathrm{m}$ ) was calculated from the depletion of the Thiabendazole concentration by adsorption [27].

For each isotherm a reference solution with an intermediate concentration was stirred without bentonite to evaluate adsorption on the glass or other losses. Analysis showed that Thiabendazole was not adsorbed on the glass of the centrifuge tubes. All adsorption experiments were made in duplicate.

\subsection{Influence of pH Values on the Adsorption of Thiabendazole}

Adsorption of Thiabendazole on bentonite was measured at various $\mathrm{pH}$ values (3, 5.5 and 9). In this procedure appropriate aliquots of an aqueous solution of 
Thiabendazole (31 mg/l) was dissolved in $1 \mathrm{~L}$ distilled water as mentioned above. Solutions of pH 3 and pH 5.5 were obtained by addition of few drops of acetic acid to distilled water in two separate jars whereas solution of pH 9 was obtained by addition of few drops of ammonium hydroxide to distilled water in a separate jar. These solutions were used for adsorption and release experiments.

In the adsorption experiments, appropriate amounts of Thiabendazole were diluted in $25 \mathrm{ml}$ with distilled water having the $\mathrm{pH}$ values mentioned above. The concentrations range of Thiabendazole in all adsorption experiments under the mentioned $\mathrm{pH}$ values were 0.0 - 31.9 $\mathrm{mg} / \mathrm{L}$. Each adsorption tube in all experiments contained $5 \mathrm{mg}$ bentonite. The adsorption solutions were maintained at $\mathrm{pH} \mathrm{3,5.5}$ and 9. The final concentration of the clay was $0.2 \mathrm{~g} / \mathrm{L}$. The supernatants were separated by centrifugation at 20,000 $\mathrm{g}$ for $1 \mathrm{~h}$, and Thiabendazole in the equilibrium solutions were determined by HPLC.

\subsection{Influence of Temperature on the Adsorption of Thiabendazole}

To measure the effect of temperature on the adsorption of Thiabendazole, the adsorption experiments mentioned above were maintained at 278, 291 and $313 \mathrm{~K}$ at $\mathrm{pH} 3$. The remaining concentrations of Thiabendazole were determined by HPLC as mentioned below, in each tube was determined by HPLC as described above.

\subsection{Preparation of Clay Based Thiabendazole Formulations}

Appropriate amounts of Thiabendazole (31 mg) were dissolved in 1 liter of distilled water to form a stock solution. Appropriate amounts of Thiabendazole $13 \mathrm{mg} / \mathrm{g}$ clay complex was added to a $1 \mathrm{~L}$ volumetric flask containing $1 \mathrm{~g}$ of clay and various $\mathrm{pH}$ solution (3 - 9). The samples were kept for $48 \mathrm{~h}$ under continuous magnetic stirring. The clay-Thiabendazole complexes were separated by centrifugation at $6000 \mathrm{~g}$, air dried and kept in plastic bottles at room temperature for use. The adsorbed amounts of Thiabendazole on the clay were determined by HPLC as mentioned above.

\subsection{Release of Thiabendazole form Clay Based Formulation}

Release of Thiabendazole from different formulations was conducted using Buchnner funnel. In this procedure, $50 \mathrm{~g}$ of air dried sandy soil was mixed through a glass cylinder with $20 \mathrm{mg}$ bentonite-Thiabendazole formulation containing $1 \mathrm{mg}$ Thiabendazole (Figure 1). The soil mixture was transferred to a Buchnner funnel $(10 \mathrm{~cm}$ internal diameter) has a filter paper in the bottom. The soil layer was homogenized to a 0.5 - $1 \mathrm{~cm}$ height. The soil layer in each funnel was carefully irrigated with 500 $\mathrm{ml}$ water having different $\mathrm{pH}$ values as mentioned above. Each volume of water (500 ml) was applied in ten portions during 2.5 hours. Each washing $(50 \mathrm{ml})$ was collected after 30 min of application in a separate flask and analyzed by HPLC to determine the released fraction of Thiabendazole. The experiment was conducted with two replications to each $\mathrm{pH}$ value.

\subsection{Data Analysis}

Adsorption data were collected as an average of 3 replicate and the standard deviation was calculated and used as error bars to discriminate differences among isotherms. Presenting the standard deviation as an error bar is the best method to determine significant differences among adsorption isotherms. Variances among treatments were analyzed by calculating p-values associated with the t-test. Values $<0.05$ indicated significant difference. It is well known that overlapping error bars indicate no difference, whereas small or extremely small error bars indicate a significant difference. Adsorption data of each isotherm were fitted by the Freundlich equation to calculate the adsorption parameters $(\mathrm{K}$, and $\mathrm{n})$.

\section{RESULTS AND DISCUSSION}

\subsection{Adsorption Kinetics}

The adsorbed amounts of Thiabendazole (Figure 1) by raw bentonite at different agitation time are shown in Figure 2. It can be seen that the adsorbed amounts are $18.33 \pm 0.63,17.82 \pm 1.17,19.09 \pm 0.43$, and $19.94 \pm 0.2$ mg/g, after 4 hr, 6 hr, 24 hr and 30 hr respectively. However, the average adsorbed amount of all cases is $18.8 \pm$ $0.92 \mathrm{mg} / \mathrm{g}$. Statistical analysis showed no significant differences among the adsorbed amount at different time.

Furthermore, it is obvious that the standard deviation is very low indicating homogeneous values of average adsorbed amounts. Accordingly, it can be suggested that $4 \mathrm{hr}$ to $6 \mathrm{hr}$ is enough agitation time for the adsorption experiments. Similar results were previously obtained for other cases [28].

\subsection{Influence of $\mathrm{pH}$ on Thiabendazole Adsorption}

Adsorption of Thiabendazole on raw bentonite at different $\mathrm{pH}$ values is shown in Figure 3. It can be seen that the highest adsorbed amount of Thiabendazole was obtained at the lowest $\mathrm{pH}$ value $(\mathrm{pH} \mathrm{3})$ and the adsorbed amount decreased as the $\mathrm{pH}$ value increased. The lowest adsorbed amount was obtained at the highest $\mathrm{pH}$ value ( $\mathrm{pH}$ 9). The explanation of these results is that $\mathrm{pH}$ value affects the ionization status of Thiabendazole. For 


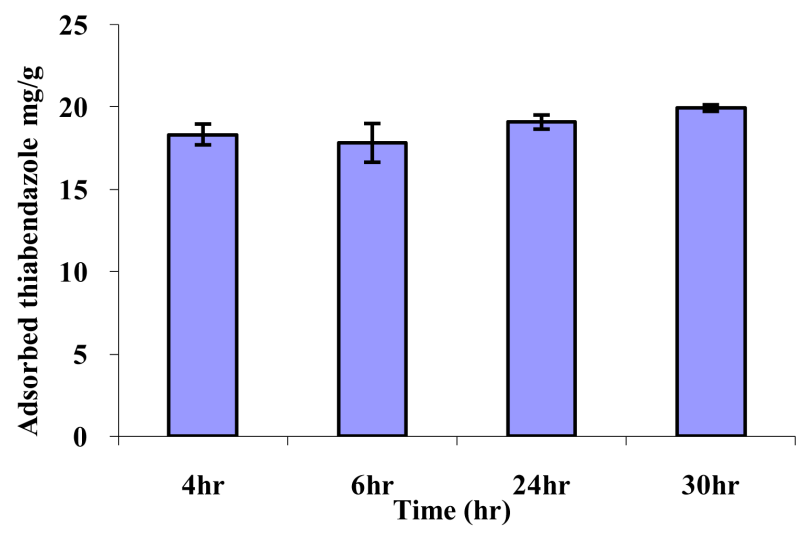

Figure 2. Adsorption kinetics of Thiabendazole on M48 at $40^{\circ} \mathrm{C}$. Bars represent standard deviation.

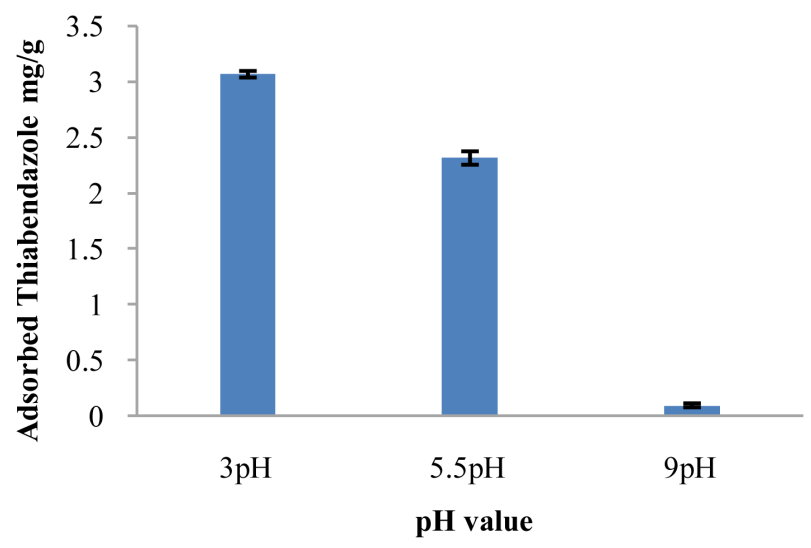

Figure 3. Adsorption of thiabendazole on M48 at different $\mathrm{pH}$ values. Bars represent standard deviation.

instance, it can be suggested that at $\mathrm{pH} 3$ or $\mathrm{pH} 5.5$ large fractions of Thiabendazole molecules became positively charged molecules consequently large adsorbed amount were obtained. At high $\mathrm{pH}$ value (pH 9) large fraction of Thiabendazole molecules became negatively charged or non charged molecules. In this case raw bentonite particles can not adsorb a negatively charged Thiabendazole molecule due to repulsion between the negatively charged bentonite surfaces and Thiabendazole. Furthermore, the hydrophilic bentonite surfaces can not adsorb large fraction from Thiabendazole molecules due to the hydrophobocity of Thiabendazole at high $\mathrm{pH}$ value. The effects of $\mathrm{pH}$ values on the ionization status of Thiabendazole molecules are shown in Figure 4. Our suggestion is supported by the previous results of El-Nahhal and Safi [29], who provided acceptable ionization status of bromoxynile adsorption on organo-clays and by Rodriguez et al [30] who achieved Thiabendazole separation using a buffer of formic acid-ammonium formate at $\mathrm{pH}$ 3.5 with $2 \%$ of methanol using solid phase extraction.

In addition, further support to our discussion can also be obtained from previous reports $[24,31]$ who provided different $\mathrm{K}_{\mathrm{ow}} \log \mathrm{P}$ values for Thiabendazole at different $\mathrm{pH}$ values.

\subsection{Adsorption Isotherms at Different pH}

Figure 5 illustrates the adsorption isotherms of Thiabendazole on bentonite clay different $\mathrm{pH}$ values. As expected, Thiabendazole was poorly adsorbed on raw bentonite (M48) high $\mathrm{pH}(\mathrm{pH}$ 9), whereas low $\mathrm{pH}(\mathrm{pH} 5.5$ and $\mathrm{pH} 3$ ) significantly enhanced the adsorbed amounts of Thiabendazole. It can be seen that at low equilibrium concentration (less than $0.5 \mathrm{mg} / \mathrm{l}$ ) a sharp increase in the adsorbed amounts of Thiabendazole was observed. Increasing Thiabendazole concentration in the equilibrium solution did not produce further increase in the adsorbed amount of Thiabendazole, and the adsorption reached to plateau. This feature of adsorption was obtained in the organic cation and clay minerals. Moreover, reaching a plateau suggests that the available adsorption site in bentonite surfaces were nearly occupied by Thiabendazole molecules. Similar feature was obtained with adsorption of cationic herbicides, paraquat and diquat, adsorption on clay [32] and organic cations to clays [25]. The explanation of $\mathrm{pH}$ effect on the adsorption of Thiabendazole is given above.

Figure 3 shows the adsorption isotherms of Thiabendazole on bentonite at various $\mathrm{pH}$ values.

Thiabendazole has an acid dissociation constant (pKa) of 4.73 and is mostly neutral at $\mathrm{pH}<4.73$, becoming deprotonated (anionic) at $\mathrm{pH}>7$.

Accordingly, the adsorbed amount of Thiabendazole obtained at $\mathrm{pH} 3$ is higher than the adsorbed amount

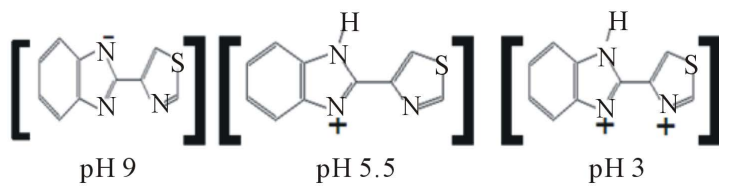

Figure 4. Influence of $\mathrm{pH}$ value on the ionization status of Thiabendazole.

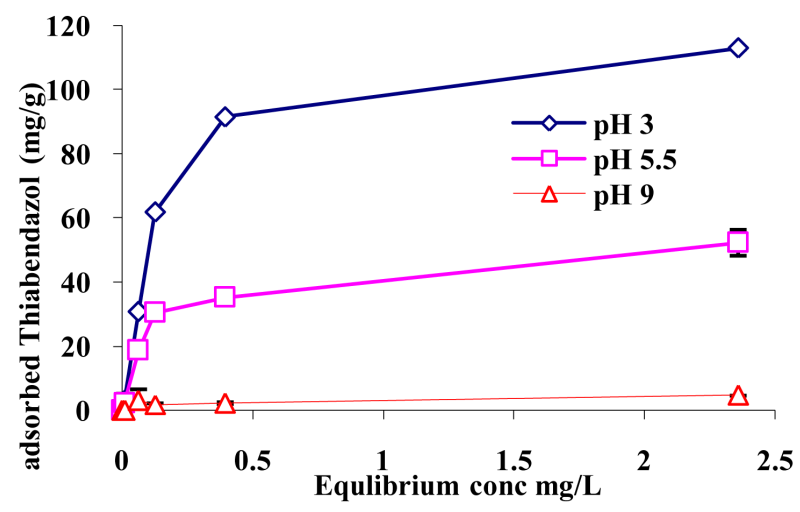

Figure 5. Adsorption of Thiabendazole on clay (M48) at various values of $\mathrm{pH}$ at $291 \mathrm{~K}$. 
obtained at pH 5.5 and pH 9 (Figure 3). Statistical analysis showed a significant difference, $\mathrm{p}$-value with t-test $=0.004$.

The high adsorbed amount at $\mathrm{pH} 3$ was because, at $\mathrm{pH}$ 3 , Thiabendazole molecules are mostly protonated, and have 2 positive charges in the $\mathrm{N}$-atoms, in this case they may be adsorbed as cations on hydrophilic sites of the bentonite surfaces. At $\mathrm{pH}$ 5.5, a part of Thiabendazole molecules has a one positive charge in the $\mathrm{N}$-atoms and the other part is in the neutral form (Figure 4). In this case, the one positive charged molecules are adsorbed on the hydrophilic sites of bentonite surfaces, and the neutral forms stay in solution; accordingly, low adsorbed amounts of Thiabendazole molecules were observed. At pH 9 the majority of Thiabendazole molecules are negatively charged or in equilibrium with the neutral form. In this case the negatively charged molecules stay in the solution due to the electronic repulsion between the anionic form of Thiabendazole and the negatively charged bentonite surfaces. Moreover, very little of the neutral Thiabendazole molecules are adsorbed the negatively charged bentonite surfaces through water bridge. The low adsorption in this case is due to the hydrophilic surface of bentonite particles and the hydrophobic properties of Thiabendazole molecules. This explanation is supported by previous reports of [29] that found a high adsorbed amount of bromoxynil in soil and wheat char at low $\mathrm{pH}$. Furthermore, the shape of the isotherm tends to be L-type and adsorption occurs as the Longmuir type at various $\mathrm{pH}$ values, due to changes in the electronic form of Thiabendazole a result of $\mathrm{pH}$ changes.

Furthermore, the shape of the isotherms was similar in all cases. According to Gile et al. [33] classification, isotherms of Thiabendazole could be classified as L type based on the initial slope of the curve in the concentration range studied. Adsorption isotherms were regular, positive and concave to the concentration axis (Figures 5 and 6), which indicated no strong competition for the adsorption sites between the solvent (water) and Thiabendazole molecules on bentonite surfaces. This suggests that Thiabendazole adsorption becomes easier as its concentration in the aqueous phase rises. These isotherms indicate the tendency of large adsorbed molecules to associate rather than to remain as isolated units. Fitting the data in Figures 5 and 6 to the Freundlich equation gives the adsorption parameter, $\left(\mathrm{Q}=\mathrm{KC} \mathrm{C}^{1 / \mathrm{n}}\right)$ where $\mathrm{Q}$ is the adsorbed amount in $\mathrm{mg} / \mathrm{g}, \mathrm{C}$ is the equilibrium concentration of Thiabendazole, $\mathrm{K}$ reflects the binding coefficient, and $\mathrm{n}$ is the physical adsorption parameter.

It can be seen in Table 1 that the $K$ value of adsorption on raw bentonite at $\mathrm{pH} 3$ is several times higher than at $\mathrm{pH} 5.5$ and $\mathrm{pH}$ 9, indication the high affinity of Thiabendazole to bentonite surfaces at low pH. Furthermore, the binding coefficient $(\mathrm{K})$ is the highest at $291 \mathrm{~K}$. This

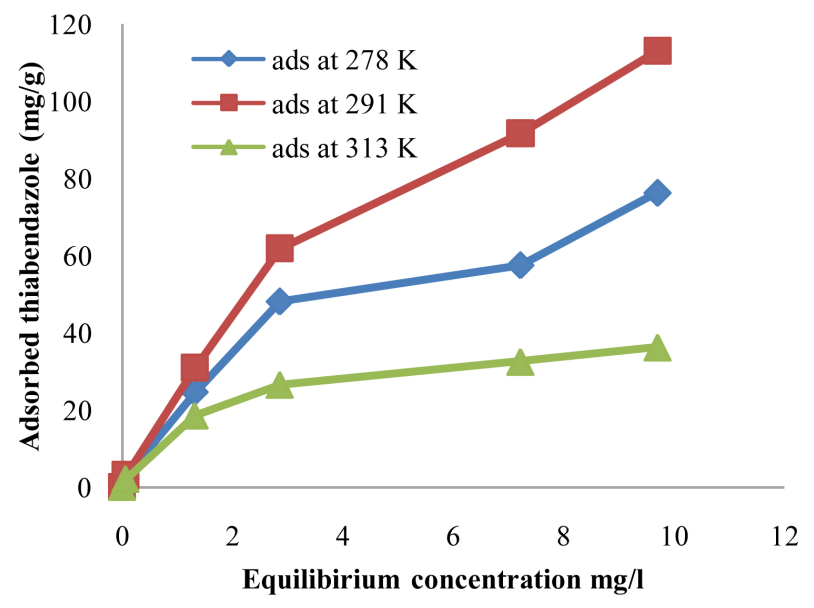

Figure 6. Influence of temperature on the adsorption of Thiabendazole on M48. Bars represent standard deviation.

Table 1. Physical parameters of Thiabendazole adsorption at different conditions.

\begin{tabular}{cccc}
\hline Adsorption condition & $\mathrm{K}$ & $\mathrm{n}$ & $\mathrm{R}^{2}$ \\
\hline pH 3 & 332 & 1.02 & 0.9392 \\
pH 5.5 & 8.41 & 1.50 & 0.9865 \\
pH 9 & 0.21 & 1.02 & 0.8634 \\
$278 \mathrm{~K}$ & 18.92 & 1.54 & 0.9839 \\
$291 \mathrm{~K}$ & 24.21 & 1.4 & 0.9936 \\
$313 \mathrm{~K}$ & 6.94 & 1.55 & 0.9571 \\
\hline
\end{tabular}

suggests that the optimum adsorption occurred at $291 \mathrm{~K}$. Furthermore, the regression values $\left(\mathrm{R}^{2}\right)$ in all cases are close to 1 indication of a strong positive association.

\subsection{Adsorption Isotherms at Different Temperature}

Adsorption of Thiabendazole at different temperature degrees are shown in Figure 6. It can be seen that adsorption of Thiabendazole is more pronounced at 291 than at $278 \mathrm{~K}$ and at $313 \mathrm{~K}$. The explanation of these results is that at a low temperature $(278 \mathrm{~K})$, the chemical potential of Thiabendazole molecules is reduced and the molecules tend to from crystals due to their low solubility in water, $0.16 \mathrm{~g} / \mathrm{l}, 20^{\circ} \mathrm{C}$ [26]. At $291 \mathrm{~K}$, nearly the optimum temperature of solubility in water, Thiabendazole molecules are very active and interact with the adsorption site at the bentonite surfaces accordingly high adsorbed amount of Thiabendazole was observed. In contrast, at high temperature (323 K), the system absorbs heat energy and an increase in the chemical potential of Thiabendazole molecules may occur. This step makes more Thiabendazole molecules in a dynamic mobility in the aqueous solution; accordingly, low adsorption was observed, indicating low adsorption affinity at high temperature. Statistical analysis of the data in Figure 6 indi- 
cates significant difference among the adsorbed amount at 278, 291 and $323 \mathrm{~K}$, as the error bars which represent the standard deviation do not overlap at any point of the equilibrium concentration (Figure 6). Furthermore calculation of p-values among the three isotherms showed value ranges between $0.034-0.029$, indicating significant differences among all cases.

This supports the suggestion that optimal adsorption occurred at temperature $291 \mathrm{~K}$.

Changes in molar free energy $\left(\Delta G^{0}\right)$ of the adsorption reaction of Thiabendazole at different temperatures were calculated using the following equation [21]:

$$
\Delta G^{o}=-R T \ln C_{i} / C_{e}
$$

where, $\Delta G^{o}$ is the molar free energy change $\left(\mathrm{Kcal} \mathrm{mol}^{-1}\right)$, $R$ is the gas constant (1.986 cal $\left.\mathrm{K}^{-1} \mathrm{~mol}\right), T$ is the absolute temperature of the adsorption reaction, and $C_{i} / C_{e}$ are the initial and equilibrium concentrations, respectively.

The values of $\Delta G^{o}$ for adsorption at $278 \mathrm{~K}, 291 \mathrm{~K}$ and $313 \mathrm{~K}$ from distilled water were $-0.802 \pm(0.313)$, $-2.147 \pm(0.504)$ and $-0.369 \pm(0.18)$, respectively. These results are in accordance with the data in Figure 6. These values are within the expected range for physical adsorption [34]. Analysis of variance between the calculated free energy at $278 \mathrm{~K}$ and 291, and between 291 and 313 gave p-values of 0.0005 and $8.86 \mathrm{E}-06$ respectively.

\subsection{Release of Thiabendazole}

The release of Thiabendazole from bentonite-Thiabendazole complexes at different $\mathrm{pH}$ values are shown in Figure 7. It is evident that \% released fraction of Thiabendazole at $\mathrm{pH} \mathrm{3,} \mathrm{pH} 5.5$ and $\mathrm{pH} 9$ are: $1.48 \pm 0.05$, $25.71 \pm 4.46$ and $79.88 \pm 9.8$ respectively. The explanation of these results is that adsorption of Thiabendazole at low $\mathrm{pH}$ values $(3,5.5)$ tends to be attraction between the positive charge of Thiabendazole (Figure 4) and the negative charge of the Ca-bentonite clay. This interactions is very strong, accordingly the release of Thiabendazole molecules from the clay surfaces depends on the $\mathrm{pH}$ of added water and the possibility of Thiabendazole molecules to form hydrogen bonding with water molecules.

Under low $\mathrm{pH}$ values ( $\mathrm{pH} 3,5.5)$, the electrostatic interactions between Thabendazole molecules and water is stronger than the hydrogen bonding with water molecules accordingly low fraction of Thabendazole is available for solubility and release at water has low $\mathrm{pH}$ value. Under high $\mathrm{pH}$ value ( $\mathrm{pH}$ 9), the electronic status of Thabendazole changed from positively charged molecules to a neutral or negatively charged ones. Accordingly the possibility of hydrogen bonding between Thabendazole and water molecules is very high beside the fact that the electrostatic interaction between Thabendazole and Cabentonite clay became very week. Accordingly, high fraction of Thabendazole is available for release as evident in Figure 7.

Kinetics of Thiabendazole release at different water volumes are shown in Figure 8. It can be seen that upon application of $0.05 \mathrm{~L}$ water (first washing) about $80 \%$ of the initial Thiabendazole concentration was released from raw bentonite-Thiabendazole complex at $\mathrm{pH}$ 9, whereas $26 \%$ and $1.5 \%$ Thiabendazole concentrations were released at $\mathrm{pH} 5.5$ and $\mathrm{pH}$ 3. Further application of eluting water up to $500 \mathrm{ml}$ resulted in the further release of Thiabendazole up to $97 \%, 70 \%$ and $2.6 \%$ from raw bentonite-Thiabendazole at $\mathrm{pH} 9, \mathrm{pH} 5.5$ and $\mathrm{pH} 3$ respectively. Thus, the release of Thiabendazole from bentonite-Thiabendazole complex at $\mathrm{pH} 3$ was significantly slower than at $\mathrm{pH} 5.5$ and $\mathrm{pH} 9$.

The explanation of these results is that the release of Thiabendazole from bentonite-Thiabendazole complexes is controlled by the binding coefficients, $(\mathrm{K})$ values, which are very high at $\mathrm{pH} 3$ and $\mathrm{pH} 5.5$ and low at $\mathrm{pH} 9$ (Table 1). These results are in agreement with a previous report [28], which found that herbicide release was controlled by binding coefficients. These results are in accordance with the adsorption data (Figure 5).

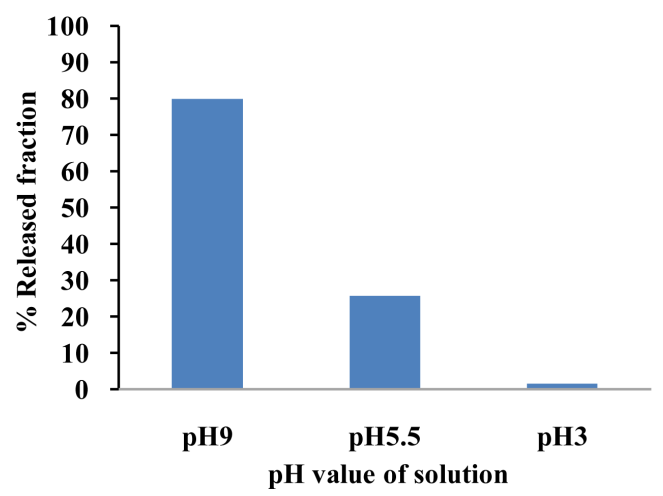

Figure 7. Influence of solution $\mathrm{pH}$ on the release fraction of Thiabendazole from bentonite (M48). Bars represent standard deviation.

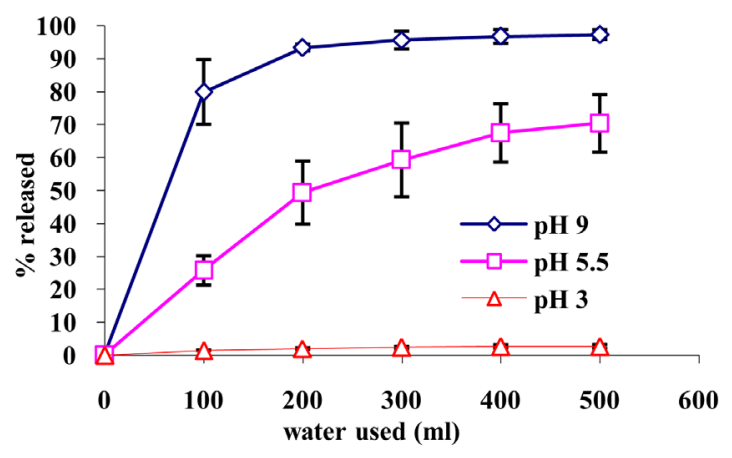

Figure 8. Kinetics of Thiabendazole release from bentonite (M48) at different solutions $\mathrm{pH}$. Bars represent standard deviation. 


\section{CONCLUDING REMARKS}

This study reveals that changing the solution $\mathrm{pH}$ of Thiabendazole resulted in changing the ionization status of the molecules and consequently enabled them to be adsorbed on the hydrophilic bentonite surfaces. The rationale for this work is that adsorption of Thiabendazole on bentonite surfaces can be enhanced by changing solution $\mathrm{pH}$. These findings showed that the highest adsorbed amounts were obtained at $\mathrm{pH} 3$ and at $291 \mathrm{~K}$ (Figures 3 and 6). The release of Thiabendazole was very slow from bentonite complexes at lower $\mathrm{pH}$ (Figures 7 and 8). The environmental relevance of this work is that bentonite clay can be used to develop environmentally acceptable Thiabendazole formulations for safe controlled release formulation.

\section{ACKNOWLEDGEMENTS}

Dr Y. El-Nahhal acknowledges Alexander von Humboldt Stiftung Foundation Fellowship Grant no IV-PAL/1104842 STP, Germany. Special thanks go to Prof Dr G.lagaly at Kiel University.

\section{REFERENCES}

[1] El-Nahhal, Y. (2004) Contamination and safety status of plant food in Arab countries. Journal of Applied Science, 4, 411-417. http://dx.doi.org/10.3923/jas.2004.411.417

[2] Dogheim, S.M., Gad Alla, S.A., El-Syes, S.M.A., Almaz, M.M. and Salama, E.Y. (1996) Organochlorine and organophosphorus pesticide residues in food from Egyptian local markets. Journal of the Association of Official Analytical Chemists, 79, 949-952.

[3] Nazer, I.K. and Masoud, H.A. (1986) Residues of diclofol on cucumber grown under plastic covers in Jordan. Journal of Environmental Science and Health Part B, 21, 387399. http://dx.doi.org/10.1080/03601238609372532

[4] Sawaya, W.N., Al-Awadhi, F.A., Saeed, T., Al-Omair, A., Ahmad, N., Husain, A., Khalafawi, S., Al-Omirah, H., Dashti, B., Al-Amiri, H. and Al-Saqer J. (1999) Kuwait's total diet study: Dietary intake of organochlorine, carbamate, benzimidazole and phenylurea pesticide residues. Journal of the Association of Official Analytical Chemists, 82, 1458-1465.

[5] Tahir, S., Anwer, T., Ahmad, I., Aziz, S., Mohammad, A. and Ahad, K. (2001) Determination of pesticide residues in fruits and vegetables in Islamabad market. Journal of Environmental Biology, 22, 71-74.

[6] Safi, J., Abou Foul, N., El-Nahhal, Y. and El-Sebae, A. (2001) Monitoring of pesticide residues on green pepper, potatoes, Vicia faba, green bean and green peas in Gaza Governarate (PNA), Palestine. Journal of Pest Control and Environmental Science, 9, 55-72.

[7] Garcia-G, J.E., Kirchhoff, J. and Grossmann F. (1990) Behavior of captafol residues after prolonged application in a wheat monoculture. Journal of Environmental Science and Health Part B, 2, 185-204. http://dx.doi.org/10.1080/03601238609372532

[8] Schirra, M., D’Aquino, S., Palma, A., Marceddu, S., Angioni, A., Cabras, P., Scherm, B. and Migheli, Q. (2005) Residue level, persistence, and storage performance of citrus fruit treated with fludioxonil. Journal of Agriculture and Food Chemistry, 53, 6718-6724.

http://dx.doi.org/10.1021/jf051004w

[9] Stromqvist, J. and Jarvis, N. (2005) Sorption, degradation and leaching of the fungicide iprodione in a golf green under Scandinavian conditions: measurements, modelling and risk assessment. Pest Management Science, 61, 11681178. http://dx.doi.org/10.1002/ps.1101

[10] Padovani, L., Capri, E., Padovani, C., Puglisi, E. and Trevisan, M. (2006) Monitoring tricyclazole residues in rice paddy watersheds. Chemosphere, 62, 303-314. http://dx.doi.org/10.1016/j.chemosphere.2005.05.025

[11] Palma, G., Sanchez, A., Olave, Y., Encina, F., Palma, R. and Barra, R. (2004) Pesticide levels in surface waters in an agricultural-forestry basin in Southern Chile. Chemosphere, 57, 763-770. http://dx.doi.org/10.1016/j.chemosphere.2004.08.047

[12] Turiel, E. and Martín, E. (2012) A Molecularly imprinted stir bars for selective extraction of thiabendazole in citrus samples. Journal of Separation Science, 35, 2962-2969. http://dx.doi.org/10.1002/jssc.201200554

[13] García-Reyes, J.F., Gilbert-López, B., Molina-Díaz, A. and Fernández-Alba, A.R. (2008) Determination of pesticide residues in fruit-based soft drinks. Analytical Chemistry, 80, 8966-8974. http://dx.doi.org/10.1021/ac8012708

[14] He, Q., Kong, X., Zhao, J., Li, J., Yue, A. and Zhang, Y. (2008) Determination of benomyl, carbendazim and thiabendazole in apple juice concentrate using solid-phase extraction coupled with ion exchange chromatography. Chinese Journal of Chromatography, 26, 563-567.

[15] Prousalis, K.P., Polygenis, D.A., Syrokou, A., Lamari, F.N. and Tsegenidis, T. (2004) Determination of carbendazim, thiabendazole, and o-phenylphenol residues in lemons by HPLC following sample clean-up by ion-pairing. Analytical and Bioanalytical Chemistry, 379, 458463. http://dx.doi.org/10.1007/s00216-004-2614-1

[16] Piccirilli, G.N. and Escandar, G.M. (2009) Flow injection analysis with on-line nylon powder extraction for roomtemperature phosphorescence determination of thiabendazole. Analytica Chimica Acta, 646, 90-96. http://dx.doi.org/10.1016/j.aca.2009.05.033

[17] Harino, H., Mori, Y., Yamaguchi, Y., Shibata, K. and Senda, T. (2005) Monitoring of antifouling booster biocides in water and sediment from the port of Osaka, Japan. Archives of Environmental Contamination and Toxicolgy, 48, 303-310. http://dx.doi.org/10.1007/s00244-004-0084-2

[18] García-Reyes, J.F., Jackson, A.U., Molina-Díaz, A. and Cooks, R.G. (2009) Desorption electrospray ionization mass spectrometry for trace analysis of agrochemicals in food. Analtical Chemistry, 81, 820-829. http://dx.doi.org/10.1021/ac802166v

[19] Grogan, H.M. and Jukes, A.A. (2003) Persistence of the fungicides thiabendazole, carbendazim and prochloraz- 
Mn in mushroom casing soil. Pest Management Science, 59, 1225-1231. http://dx.doi.org/10.1002/ps.759

[20] Castillo, L.E., Martínez, E., Ruepert, C., Savage, C., Gilek, M., Pinnock, M. and Solis, E. (2006) Water quality and macroinvertebrate community response following pesticide applications in a banana plantation, Limon, Costa Rica. The Science of the Total Environment, 367, 418-432. http://dx.doi.org/10.1016/j.scitotenv.2006.02.052

[21] Kim, H.J., Lee, D.S. and Kwon, J.H. (2010) Sorption of benzimidazole anthelmintics to dissolved organic matter surrogates and sewage sludge. Chemosphere, 80, 256262.

http://dx.doi.org/10.1016/j.chemosphere.2010.04.029

[22] García-Calzón, J.A., Muñíz-Alvarez, J.L. and LópezFonseca, J.M. (1999) Adsorption and two-dimensional condensation of thiabendazole at a mercury/solution interface. Journal of Colloid and Interface Science, 219, 144-148. http://dx.doi.org/10.1006/jcis.1999.6455

[23] Spanoghe, P., Ryckaert, B., Van-Gheluwe, C. and VanLabeke, M.C. (2008) Fate of vinclozolin, thiabendazole and dimethomorph during storage, handling and forcing of chicory. Pest Management Science, 66, 126-131. http://dx.doi.org/10.1002/ps.1838

[24] USEPA Prevention, Pesticides and Toxic Substances (2002) Thiabendazole and salts. EPA-738-F-02-002.

[25] El-Nahhal, Y., Nir, S., Polubesova, T., Margulies, L. and Rubin, B. (1998) Leaching, phytotoxicity and weed control of new formulations of alachlor. Journal of Agricultural Food Chemistry, 46, 3305-3313. http://dx.doi.org/10.1021/jf971062k

[26] Tomlin, C.D. (2000) The pesticides manual. 11th Edition, British Crop Protection Council.

[27] El-Nahhal, Y. and Lagaly, G. (2005) Salt effects on the adsorption of a pesticide on modified bentonite. Colloid and Polymer Science, 283, 968-974.

http://dx.doi.org/10.1007/s00396-004-1244-7

[28] El-Nahhal, Y. and Safi, J. (2006) Bentonite for controlled release of linuron. Journal of Pest Control and Environmental Science, 14, 57-71.

[29] El-Nahhal, Y. and Safi, J. (2010) Adsorption of bromoxynil to modified bentonite: Influence of $\mathrm{pH}$, and temperature. Journal of Pesticide Science, 35, 333-338. http://dx.doi.org/10.1584/jpestics.G09-41

[30] Rodríguez, R., Picó, Y., Font, G. and Mañes, J. (2002) Analysis of thiabendazole and procymidone in fruits and vegetables by capillary electrophoresis-electrospray mass spectrometry. Journal of Chromatography A, 949, 359366. http://dx.doi.org/10.1016/S0021-9673(01)01395-4

[31] European Commission, Directorate-General Health and Comsumer Protection (2001) Thiabendazole. 7603/VI/97Final, 22 March 2001.

[32] Rytwo, G. and Tavasi, M. (2003) Addition of a monovalent cationic pesticide to improve efficacy of bipyridyl herbicides in Hulah Valley soils. Pest Management Science, 59, 1265-1270. http://dx.doi.org/10.1002/ps.732

[33] Giles, C.H., Mac-Ewan, T.H., Nakhwa, S.N. and Smith, D.A. (1960) System of classification of solution adsorption isotherms, and its use in diagnosis of adsorption mechanisms and in measurement of specific surface areas of solids. Chemical Society, 111, 3973-3993.

[34] Kishk, M.F., Abu-Sharar, M.T., Bakry M.N. and AbuDonia B.M. (1979) Sorption-desorption characteristics of methyl parathion by clays. Archives of Environmental Contamination and Toxicology, 8, 637-645. http://dx.doi.org/10.1007/BF01054866 